\title{
Primary care patient willingness for genetic testing for salt-sensitive hypertension: a cross sectional study
}

\author{
Masanobu Okayama ${ }^{*}$, Taro Takeshima', Ryusuke $\mathrm{Ae}^{2}$, Masanori Harada ${ }^{3}$ and Eiji Kajii ${ }^{1}$
}

\begin{abstract}
Background: The current research into single nucleotide polymorphisms has extended the role of genetic testing to the identification of increased risk for common medical conditions. Advances in genetic research may soon necessitate preparation for the role of genetic testing in primary care medicine. This study attempts to determine what proportion of patients would be willing to undergo genetic testing for salt-sensitive hypertension in a primary care setting, and what factors are related to this willingness.
\end{abstract}

Methods: A cross-sectional study using a self-report questionnaire was conducted among outpatients in primary care clinics and hospitals in Japan. The main characteristics measured were education level, family medical history, personal medical history, concern about hypertension, salt preference, reducing salt intake, and willingness to undergo genetic testing for salt-sensitive hypertension.

Results: Of 1,932 potential participants, 1,457 (75\%) responded to the survey. Of the respondents, 726 (50\%) indicated a willingness to undergo genetic testing. Factors related to this willingness were being over 50 years old (adjusted odds ratio [ad-OR] $=1.42,95 \%$ Confidence interval $=1.09-1.85$ ), having a high level of education (ad-OR: $1.83,1.38-2.42$ ), having a family history of hypertension (ad-OR: 1.36, $1.09-1.71$ ), and worrying about hypertension (ad-OR: 2.06, 1.59 - 2.68).

Conclusions: Half of the primary care outpatients surveyed in this study wanted to know their genetic risk for salt-sensitive hypertension. Those who were worried about hypertension or had a family history of hypertension were more likely to be interested in getting tested. These findings suggest that primary care physicians should provide patients with advice on genetic testing, as well as address their anxieties and concerns related to developing hypertension.

Keywords: Attitudes, Genetic testing, Salt-sensitive hypertension, Primary care, Outpatient

\section{Background}

During the past few years, there has been an explosion in genomics; the advent of genome-wide association studies has revealing hundreds of deoxyribonucleic acid (DNA) variants significantly associated with common diseases [1,2]. This advance holds the promise of personalized medicine, with the potential to enhance human health through more effective prevention, diagnosis, and treatment, [3] and direct-to-consumer genetic testing

\footnotetext{
* Correspondence: okayama@jichi.ac.jp

${ }^{1}$ Division of Community and Family Medicine, Center for Community Medicine, Jichi Medical University, Yakushiji 3311-1, Shimotsuke-city, Tochigi 329-0498, Japan

Full list of author information is available at the end of the article
}

services provided by private companies are rapidly increasing in popularity [4]. Genetic testing is becoming increasingly accessible to anyone who wishes to obtain information about his or her genetic profile.

Genomics research has traditionally focused on rare conditions, such as hereditary diseases. However, the current research into single nucleotide polymorphisms has extended the role of genetic testing to the identification of increased risk for common medical conditions, [2] as well as lifestyle-enhancing information. For example, nutrigenetics uses genetic information to provide personalized diet and lifestyle advice [5]. Many consumers of direct-to-consumer personal genetic testing 
are expected to seek physician advice to help them make sense of their test results, [6] increasing the need for advice on genetic testing in all branches of medicine-especially primary care [7]. In addition to reproductive risks, adultonset Mendelian inheritance disorders, and normal genetic variations in drug metabolism, common diseases with multifactorial etiologies, such as cardiovascular disease, diabetes mellitus, and hypertension are categories of genetic medicine that are relevant in primary care $[7,8]$.

To appropriately explain the results of genetic testing, practitioners must better understand patients' awareness of genetic testing. Most previous studies exploring awareness of genetic testing were conducted using patients with various forms of cancer, such as beast, [9] colorectal, [10] and ovarian cancer [11]. Studies have also focused on patients attending cancer clinics, [12-14] or receiving direct-to-consumer genetic testing [15]. Two studies performed in primary care settings examined awareness of genetic risk of hereditary diseases [16] and breast cancer [17]. However, the proportion of primary care patients who are willing to undergo genetic testing for common diseases, aside from cancer, remains unknown.

Treatment of hypertension is the most common reason for primary care outpatient visits for non-pregnant adults in both the United States [18] and Japan [19]. Excessive salt intake is associated with increased blood pressure, [20] but several gene polymorphisms associated with salt-sensitive hypertension have also been identified [21]. Consequently, it seems desirable to clarify what proportion of patients would be willing to undergo genetic testing for salt-sensitive hypertension, and what factors were related to this willingness in outpatients from a primary care setting. The present study attempts to fill this gap.

\section{Methods \\ Study design}

This cross-sectional study used a self-administered questionnaire.

\section{Participants and measurements}

Anonymous questionnaires were distributed to consecutive outpatients over 20 years old who visited the primary care departments of three clinics and two small hospitals in Japan. Data were collected during two-week periods at each clinic or hospital, from September to December 2009. Research assistances handed out the questionnaires to the patients at the reception counter and told that they were not remunerated for participation and could decline to participate without penalty. The patients filled out the questionnaire in the waiting room. Primary care physicians were not informed as to whether patients answered the questionnaire or not.
The questionnaire asked about participants' age, sex, education level, occupation ("Are you a healthcare worker?" [yes/no]), family and personal medical history (with regard to hypertension, diabetes mellitus, stroke, and myocardial infarction), body mass index (BMI), worries about hypertension and diabetes mellitus ("Do you worry about hypertension" and "Do you worry about diabetes mellitus", respectively), salt preference ("Do you prefer salty foods?"), current lifestyle behaviors (smoking, drinking, regular exercise, and reducing salt intake), and willingness to undergo genetic testing for salt-sensitive hypertension ("Would you want to undergo genetic testing that detected whether or not you have a genetic risk predisposing you to hypertension by excessive salt intake?" ). We a provided a description of genetic testing for salt-sensitive hypertension, but no any additional information.

\section{Analysis}

Statistical analyses were performed using STATA/SE version 12.1 (Stata Corp LP, College Station, Texas, TX, US). The significance threshold was set at 0.05. Descriptive statistics were mean \pm standard deviation (SD) for age, and proportion for all other variables. Participant age was divided into three categories (less than 50 years old, 50-64, and 65 and over) and proportion was calculated for each category. Obesity was defined as having a BMI greater than 25. The Japanese have defined obesity as any BMI greater than 25 [22]. Chi-square tests were used to compare the proportion of patients for each item who were or were not willing to undergo genetic testing.

We conducted logistic regression analyses to determine factors related to willingness to undergo genetic testing. For these analyses, the sample was divided dichotomously on the basis of age into over-50-years old and under-50-years groups. On the basis of the patients' answers regarding education level, persons who had graduated college and university were classified as the high education group, while all others were classified as the non-high education group. Using univariate analysis, crude odds ratios (ORs) and 95\% confidence intervals (CIs) were calculated for age, sex, education level, occupation, family medical history, personal medical history, obesity, worries about hypertension and diabetes mellitus, salt preference, and four current lifestyle behaviors. Adjusted ORs (95\% CI) were then obtained, adjusting for variables that were significantly related in the univariate analyses.

\section{Ethics}

Approval was obtained for the study protocol and questionnaire from the Jichi Medical University Review Board. 


\section{Results}

Of the 1,932 outpatients who visited the study sites during the study period, 1,457 (75\% response rate) completed the survey (males: 552; 38\%). Mean age of participants was $58.1 \pm 17.3$ years, and $726(50 \%)$ were willing to undergo genetic testing for salt-sensitive hypertension (Table 1).

Table 2 gives a comparison of the proportions of patients for each item who were and were not interesting in genetic testing. We found no significant differences for salt preference or reducing salt intake between patients who were and were not interesting in genetic testing. Of the participants with and without family histories of hypertension, $43 \%$ and $32 \%$ were willing to be tested, respectively (chi-square test, $\mathrm{p}<0.001$ ). Of the participants who worried or did not worry about hypertension, $64 \%$ and $46 \%$ were willing to be tested, respectively (chisquare test, $\mathrm{p}<0.001$ ).

Univariate logistic regression analysis (Table 3) showed that the factors related to participants' willingness to undergo genetic testing were being over 50 years old (crude OR: 1.30, 95\% CI: 1.04-1.62), being a healthcare worker $(1.80,1.18-2.76)$, being in the high education group (1.60, 1.26-2.02), having a family history of hypertension $(1.66,1.34-2.05)$ or stroke $(1.45,1.10-1.90)$, having a personal medical history of hypertension (1.40, $1.12-1.74)$, and worrying about hypertension $(2.18,1.77-$ 2.69) or diabetes mellitus (1.36, 1.11-1.68). Multivariate logistic regression analysis identified being over 50 years old (adjusted OR [ad-OR]: 1.42, 95\% CI: 1.09-1.85), being in the high education group (ad-OR: 1.83, 1.38-2.42), having a family history of hypertension (ad-OR: 1.36, 1.091.71), and worrying about hypertension (ad-OR: 2.06, $1.59-2.68)$ as independently related to willingness to undergo genetic testing.

\section{Discussion}

This study answered the question of what proportion of outpatients visiting primary care clinics and hospitals are willing to undergo genetic testing for saltsensitive hypertension, and what factors are related to this willingness. This study found that exactly half of the patients in a primary care setting wanted to have their genetic risk of salt sensitivity hypertension assessed. This is consistent with the $43-76 \%$ rate at which participants in other studies, including cancer patients, the relatives of cancer patients, and attendees of the educational component of a breast cancer awareness campaign, have been interested in genetic testing for cancers and hereditary diseases in previous studies $[9,12,13,16,17]$.

Half of patients with chronic diseases consider their primary care physician to be the preferred source of information about the role of genetics in their health [6]. However, the vast majority of single nucleotide polymorphisms are associated with very low odds ratios for
Table 1 Demographic characteristics $(N=1,457)$

\begin{tabular}{|c|c|}
\hline & $n(\%)$ \\
\hline Age in years (mean $\pm S D$ ) & $(58.1 \pm 17.3)$ \\
\hline$<50$ & $469(32)$ \\
\hline $50-64$ & $406(28)$ \\
\hline $65+$ & $582(40)$ \\
\hline \multicolumn{2}{|l|}{ Sex } \\
\hline Male & $552(38)$ \\
\hline Female & $905(62)$ \\
\hline \multicolumn{2}{|l|}{ Occupation } \\
\hline Healthcare worker & $98(7)$ \\
\hline Not a healthcare worker & $1,359(93)$ \\
\hline \multicolumn{2}{|l|}{ Education level } \\
\hline Elementary school & $102(7)$ \\
\hline Junior high school & $393(27)$ \\
\hline High school & $575(40)$ \\
\hline College & $291(20)$ \\
\hline University & $96(7)$ \\
\hline \multicolumn{2}{|l|}{ Family medical history } \\
\hline Hypertension & $550(38)$ \\
\hline Diabetes mellitus & $195(13)$ \\
\hline Stroke & $256(18)$ \\
\hline Myocardial infarction & $120(8)$ \\
\hline \multicolumn{2}{|l|}{ Personal medical history } \\
\hline Hypertension & $499(34)$ \\
\hline Diabetes & $167(12)$ \\
\hline Stroke & $32(2)$ \\
\hline Myocardial infarction & $35(2)$ \\
\hline Obesity (BMI > 25) & $293(20)$ \\
\hline \multicolumn{2}{|l|}{ Worries about } \\
\hline Hypertension & $800(53)$ \\
\hline Diabetes & $706(49)$ \\
\hline \multicolumn{2}{|l|}{ Salt preference } \\
\hline Prefers salty foods & $869(60)$ \\
\hline Dose not prefer salty foods & $588(40)$ \\
\hline \multicolumn{2}{|l|}{ Current lifestyle behaviors } \\
\hline Smoke & $241(17)$ \\
\hline Drink & $585(40)$ \\
\hline Regularly exercise & $578(40)$ \\
\hline Reducing salt intake & $796(55)$ \\
\hline Willingness to be tested & $726(50)$ \\
\hline
\end{tabular}

Note: $\mathrm{SD}=$ standard deviation, $\mathrm{BMI}=$ body mass index.

common diseases [23]. Furthermore, genetic polymorphisms related to salt-sensitive hypertension are not a major contributor to increased blood pressure [24,25]. Although genetic testing to predict common diseases 
Table 2 Comparison of participants who were and were not willing to undergo genetic testing

\begin{tabular}{|c|c|c|c|}
\hline & $\begin{array}{c}\text { Willing } \\
(n=726), n(\%)\end{array}$ & $\begin{array}{c}\text { Not willing } \\
(n=731), n(\%)\end{array}$ & $p$ value * \\
\hline Age in years & & & 0.004 \\
\hline$<50$ & $213(29)$ & $256(35)$ & \\
\hline $50-64$ & $229(32)$ & $177(24)$ & \\
\hline $65+$ & 284 (39) & $298(41)$ & \\
\hline Sex & & & 0.446 \\
\hline Male & $268(37)$ & $284(39)$ & \\
\hline Female & $458(63)$ & $447(62)$ & \\
\hline Occupation & & & 0.006 \\
\hline Healthcare worker & $62(9)$ & $36(5)$ & \\
\hline $\begin{array}{l}\text { Not a healthcare } \\
\text { worker }\end{array}$ & 664 (91) & $695(95)$ & \\
\hline Education level & & & $<0.001$ \\
\hline Elementary school & $37(5)$ & $65(9)$ & \\
\hline Junior high school & $188(26)$ & $205(28)$ & \\
\hline High school & $275(38)$ & $300(41)$ & \\
\hline College & $173(24)$ & $118(16)$ & \\
\hline University & $53(7)$ & $43(6)$ & \\
\hline \multicolumn{4}{|l|}{ Family medical history } \\
\hline Hypertension & $317(44)$ & $233(32)$ & $<0.001$ \\
\hline Diabetes mellitus & $100(14)$ & $95(13)$ & 0.663 \\
\hline Stroke & $147(20)$ & $109(15)$ & 0.007 \\
\hline Myocardial infarction & $59(8)$ & $61(8)$ & 0.880 \\
\hline \multicolumn{4}{|l|}{ Personal medical history } \\
\hline Hypertension & $276(38)$ & $223(31)$ & 0.003 \\
\hline Diabetes & $85(12)$ & $82(11)$ & 0.769 \\
\hline Stroke & $20(3)$ & $12(2)$ & 0.147 \\
\hline Myocardial infarction & $17(2)$ & $18(2)$ & 0.880 \\
\hline Obesity (BMI > 25) & $153(21)$ & $140(19)$ & 0.360 \\
\hline \multicolumn{4}{|l|}{ Worries about } \\
\hline Hypertension & $468(64)$ & $332(45)$ & $<0.001$ \\
\hline Diabetes & $380(52)$ & $326(45)$ & 0.003 \\
\hline Salt preference & & & 0.109 \\
\hline Prefers salty foods & $448(62)$ & $421(57)$ & \\
\hline $\begin{array}{l}\text { Dose not prefer salty } \\
\text { foods }\end{array}$ & $278(38)$ & $310(43)$ & \\
\hline \multicolumn{4}{|l|}{ Current lifestyle behavior } \\
\hline Smoke & $108(15)$ & $133(18)$ & 0.088 \\
\hline Drink & $296(41)$ & $289(40)$ & 0.630 \\
\hline Regularly exercise & $285(39)$ & $293(40)$ & 0.747 \\
\hline $\begin{array}{l}\text { Cutting down on salt } \\
\text { intake }\end{array}$ & $406(56)$ & $390(53)$ & 0.324 \\
\hline
\end{tabular}

Note: $\mathrm{Cl}=$ confidence interval, $\mathrm{BMI}=$ body mass index. ${ }^{*}$ chi-square test.
Table 3 Factors related to participant willingness to undergo genetic testing

\begin{tabular}{|c|c|c|}
\hline & $\begin{array}{c}\text { Crude OR } \\
(95 \% \mathrm{Cl})\end{array}$ & $\begin{array}{c}\text { Adjusted OR } \\
(95 \% \mathrm{Cl}) \\
\end{array}$ \\
\hline Age: $\geq 50$ years & $1.30(1.04-1.62)$ & $1.42(1.09-1.85)$ \\
\hline Sex: male & $0.92(0.75-1.14)$ & \\
\hline \multicolumn{3}{|l|}{ Occupation } \\
\hline Healthcare worker & $1.80(1.18-2.76)$ & $1.34(0.83-2.17)$ \\
\hline \multicolumn{3}{|l|}{ Education level } \\
\hline High education group & $1.60(1.26-2.02)$ & $1.83(1.38-2.42)$ \\
\hline \multicolumn{3}{|l|}{ Family medical history } \\
\hline Hypertension & $1.66(1.34-2.05)$ & $1.36(1.09-1.71)$ \\
\hline Diabetes mellitus & $1.07(0.79-1.45)$ & - \\
\hline Stroke & $1.45(1.10-1.90)$ & $1.24(0.93-1.66)$ \\
\hline Myocardial infarction & $0.97(0.67-1.41)$ & - \\
\hline \multicolumn{3}{|l|}{ Personal medical history } \\
\hline Hypertension & $1.40(1.12-1.74)$ & $0.96(0.73-1.25)$ \\
\hline Diabetes & $1.05(0.76-1.45)$ & - \\
\hline Stroke & $1.70(0.82-3.50)$ & - \\
\hline Myocardial infarction & $0.95(0.49-1.86)$ & - \\
\hline Obesity (BMI > 25) & $1.13(0.87-1.46)$ & - \\
\hline \multicolumn{3}{|l|}{ Worry about } \\
\hline Hypertension & $2.18(1.77-2.69)$ & $2.06(1.59-2.68)$ \\
\hline Diabetes & $1.36(1.11-1.68)$ & $1.02(0.80-1.29)$ \\
\hline Salt preference & $1.19(0.96-1.46)$ & - \\
\hline \multicolumn{3}{|l|}{ Current lifestyle behavior } \\
\hline Smoke & $0.79(0.60-1.04)$ & - \\
\hline Drink & $1.05(0.85-1.30)$ & - \\
\hline Regularly exercise & $0.97(0.78-1.19)$ & - \\
\hline Cutting down on salt intake & $1.11(0.90-1.36)$ & - \\
\hline
\end{tabular}

may not yet be available or practical in a primary care setting, the findings in this study indicate that, in the near future, primary care physicians are likely to find that genetic testing and providing advice on genetic testing results are playing a role in their day-to-day practice.

In the present study, no relationships were found between participants' salt preference or reducing salt intake and their willingness to undergo genetic testing for salt-sensitive hypertension. However, genetic risk information can improve information about nutrition for optimal personal health; [26] in other words, knowing whether one had a salt sensitivity for hypertension or not could contribute to patients' decisions to modify their salt intake or maintain current eating habits. We were surprised that, in the present study, participants' preference for a salty taste was in no way related to their willingness to be tested for genetic risk. The findings in this study suggest that disclosing the genetic 
testing results regarding salt-sensitive hypertension may have little influence on behavioral modification of salt intake. Therefore, future studies should clarify the effects of genetic information regarding risk of salt sensitive hypertension on behavioral changes. In this way, nutrigenetics concerning salt intake could be applied to the primary care setting.

Findings from the present study indicate that age (over 50), a high level of education, a family history of hypertension, and worrying about hypertension were independent factors positively related to willingness to undergo genetic testing for salt-sensitive hypertension. These factors were consistent with previous studies on willingness to be tested for genetic risk of cancer and other hereditary disease $[11-13,16,17]$. On the basis of these findings, it appears that, regardless of the kind of disease in question, the aforementioned factors might related to general willingness to be tested for genetic risk.

Behavioral modification is more efficient in preventing hypertension in people younger than 50 than in people over 50 . However, the findings in the present study indicate that people over 50 years old are more willing than their younger counterparts to undergo genetic testing for salt-sensitive hypertension. Although the positive effects of knowing one's genetic risk profile on making positive behavioral changes has been established, this benefit can, of course, not be achieved without first undergoing genetic testing. Therefore, improved motivation among patients to know more about their genetic risk of salt-sensitive hypertension can translate into clinically meaningful, cost-effective changes in outcomes for hypertensive patients. More positive changes can be made by finding ways to encourage patients younger than 50 years old to agree to undergo genetic testing for their risk of salt-sensitive hypertension.

Of course, genetic testing has a potential for causing anxiety and distress, especially if a patient learns that he or she is at increased risk for a serious illness. This is exacerbated by the fact that patients expect genetic testing to precisely predict whether they will develop a specific disease, and that genetic testing will improve their ability to manage this disease; they are often unable to grasp the uncertain nature of the information currently available from genetic testing $[27,28]$. However, a test result- positive and negative-can bring relief from uncertainty and help patients to make informed medical and lifestyle decisions, including taking steps to improve their health-seeking behaviors $[29,30]$. There is still significant disagreement as to whether genetic testing is overall anxiety causing or reducing, and whether it would be therefore indicated for all consumers. Further, Two studies have reported that information from direct-to-consumer genetic testing causes no additional anxiety to consumers $[31,32]$.
However, a different study reported that testing positive for increased genetic risk of illness was associated with high levels of anxiety and depression [33]. Another study warned that heightened, unnecessary anxiety was a potential negative consequence of genetic testing [34]. While there is still disagreement over the larger issue of genetic testing, the present finding about the role of worrying about hypertension indicates that when disclosing the results of genetic testing, primary care physicians should keep in mind the potential for patients to feel anxious and concerned about developing hypertension, and to offer advice and explanations along with test results. For example, when discussing the results of genetic testing, primary care physicians should be specific, rather than general.

Despite its contributions, this study has several limitations. First, we assessed participant interest in genetic testing without taking into account the factors of cost and level of understanding of genetic testing, simply providing a description of genetic testing for salt-sensitive hypertension. Second, preference for salty foods was assessed using self-report; we did not measure actual daily salt intake. However, patient preference for salty foods does not always correlate with salt intake [35]. Future studies should explore the relationship between actual daily salt intake and willingness to be tested for genetic risk of salt-sensitive hypertension. Third, this study used self-report data, and self-reporting frequently results in considerable error in data presentation. In addition, patients who were highly educated may perform different healthy behaviors from those they reported. These methodological weaknesses might have influenced findings regarding the relationships between salt preference, current lifestyle behaviors, and the willingness to undergo genetic testing. Fourth, although study findings were consistent with those obtained previously in samples using patients of different nationalities, the participants in this study were all Japanese, and cultural, dietary, and genetic differences might have diminished or reinforced the applicability of the findings in this study to other countries. Finally, this study did not assess perceived benefits of genetic testing, such as in predicting the development of hypertension or improving the management of hypertension. This issue possibly influences the proportion of patients who are willing to undergo genetic testing.

\section{Conclusions}

With the rapid advances in genetics research, patients will increasingly have the option to undergo genetic testing for common diseases. In the near future, this may mean that primary care physicians will be required to prepare to advise patients on questions of genetic risk concerning common diseases such as hypertension. Physicians will 
need to be informed about what information would be most helpful to their patients, what patients are more or less likely to be willing to undergo genetic testing, and how patients will use this information to shape healthpromoting behaviors.

\section{Abbreviations}

BMI: Body mass index; Cl: Confidence interval; DNA: Deoxyribonucleic acid; OR: Odds ratio; SD: Standard deviation.

\section{Competing interests}

The authors declare that they have no competing interests.

\section{Authors' contributions}

MO contributed to conception and design, acquisition of data, analysis and interpretation of data, and writing and revision of the manuscript. $\Pi$ T contributed to conception and design and analysis and interpretation of data. RA and $\mathrm{MH}$ contributed to acquisition, analysis, and interpretation of data. EK contributed to conception and design and writing and revision of the manuscript. All authors approved the final version of the manuscript to be published.

\section{Acknowledgements}

We thank S Fujiwara, MD, PhD; D Matsuhima, MD, PhD; K Nakayasu, MD; C Ishida, MD; Y Ishibashi, MD; S Ohguri; R Kobayashi, and K Kawabata for their assistance with data collection. This study was supported by a Grant-in-Aid for Scientific Research (B) (21390168) from the Japan Society for the Promotion of Science.

\section{Author details}

${ }^{1}$ Division of Community and Family Medicine, Center for Community Medicine, Jichi Medical University, Yakushiji 3311-1, Shimotsuke-city, Tochigi 329-0498, Japan. ${ }^{2}$ Division of Public Health, Center for Community Medicine, Jichi Medical University, Yakushiji 3311-1, Shimotsuke-city, Tochigi 329-0498, Japan. ${ }^{3}$ Department of Support of Rural Medicine, Yamaguchi Grand Medical Center, Ohsaki 77, Hofu, Yamaguchi 747-8511, Japan.

\section{Received: 1 August 2013 Accepted: 7 October 2013}

\section{Published: 9 October 2013}

\section{References}

1. Manolio TA, Collins FS, Cox NJ, Goldstein DB, Hindorff LA, Hunter DJ, McCarthy MI, Ramos EM, Cardon LR, Chakravarti A, et al: Finding the missing heritability of complex diseases. Nature 2009, 461(7265):747-753.

2. A Catalog of Published Genome-Wide Association Studies. [https://www. genome.gov/GWAStudies/]

3. Tuckson RV, Newcomer L, De Sa JM: Accessing genomic medicine: affordability, diffusion, and disparities. JAMA 2013, 309(14):1469-1470.

4. Borry P, Cornel MC, Howard HC: Where are you going, where have you been: a recent history of the direct-to-consumer genetic testing market. J Community Genet 2010, 1(3):101-106.

5. Mutch DM, Wahli W, Williamson G: Nutrigenomics and nutrigenetics: the emerging faces of nutrition. FASEB J 2005, 19(12):1602-1616.

6. Morren M, Rijken M, Baanders AN, Bensing J: Perceived genetic knowledge, attitudes towards genetic testing, and the relationship between these among patients with a chronic disease. Patient Educ Couns 2007, 65(2):197-204.

7. Emery J, Hayflick S: The challenge of integrating genetic medicine into primary care. BMJ 2001, 322(7293):1027-1030.

8. Scheuner MT, Wang SJ, Raffel L, Larabell SK, Rotter Jl: Family history: a comprehensive genetic risk assessment method for the chronic conditions of adulthood. Am J Med Genet 1997, 71(3):315-324.

9. O'Neill SC, Brewer NT, Lillie SE, Morrill EF, Dees EC, Carey LA, Rimer BK: Women's interest in gene expression analysis for breast cancer recurrence risk. J Clin Oncol 2007, 25(29):4628-4634.

10. Esplen MJ, Madlensky L, Aronson M, Rothenmund H, Gallinger S, Butler K, Toner B, Wong J, Manno M, McLaughlin J: Colorectal cancer survivors undergoing genetic testing for hereditary non-polyposis colorectal cancer: motivational factors and psychosocial functioning. Clin Genet 2007, 72(5):394-401.
11. Metcalfe KA, Fan I, McLaughlin J, Risch HA, Rosen B, Murphy J, Bradley L, Armel S, Sun P, Narod SA: Uptake of clinical genetic testing for ovarian cancer in Ontario: a population-based study. Gynecol Oncol 2009, 112(1):68-72.

12. Mogilner A, Otten M, Cunningham JD, Brower ST: Awareness and attitudes concerning BRCA gene testing. Ann Surg Oncol 1998, 5(7):607-612.

13. Collins V, Halliday J, Warren R, Williamson R: Cancer worries, risk perceptions and associations with interest in DNA testing and clinic satisfaction in a familial colorectal cancer clinic. Clin Genet 2000, 58(6):460-468.

14. Bruno M, Digennaro M, Tommasi S, Stea B, Danese T, Schittulli F, Paradiso A: Attitude towards genetic testing for breast cancer susceptibility: a comparison of affected and unaffected women. Eur J Cancer Care (Engl) 2010, 19(3):360-368.

15. Bloss CS, Ornowski L, Silver E, Cargill M, Vanier V, Schork NJ, Topol EJ: Consumer perceptions of direct-to-consumer personalized genomic risk assessments. Genet Med 2010, 12(9):556-566.

16. Anderson RT, Press N, Tucker DC, Snively BM, Wenzel L, Ellis SD, Hall MA, Walker AP, Thomson EJ, Lewis-Jack O, et al: Patient acceptability of genotypic testing for hemochromatosis in primary care. Genet Med 2005, 7(8):557-563.

17. Amin TT, Al-Wadaani HA, Al-Quaimi MM, Aldairi NA, Alkhateeb JM, Al-Jaafari AA: Saudi women's interest in breast cancer gene testing: possible influence of awareness, perceived risk and socio-demographic factors. Asian Pac J Cancer Prev 2012, 13(8):3879-3887.

18. Egan BM, Zhao Y, Axon RN: US trends in prevalence, awareness, treatment, and control of hypertension, 1988-2008. JAMA 2010, 303(20):2043-2050.

19. National Health and Nutrition Examination Survey 2011. [http://www.mhlw. go.jp/stf/houdou/2r9852000002q1st-att/2r9852000002q1wo.pdf]

20. Intersalt Cooperative Research Group: Intersalt: an international study of electrolyte excretion and blood pressure. Results for 24 hour urinary sodium and potassium excretion. Intersalt Cooperative Research Group. BMJ 1988, 297(6644):319-328.

21. Katsuya T, Ishikawa K, Sugimoto K, Rakugi H, Ogihara T: Salt sensitivity of Japanese from the viewpoint of gene polymorphism. Hypertens Res 2003, 26(7):521-525

22. Kanazawa M, Yoshiike N, Osaka T, Numba Y, Zimmet P, Inoue S: Criteria and classification of obesity in Japan and Asia-Oceania. World Rev Nutr Diet 2005, 94:1-12.

23. Khoury MJ, McBride CM, Schully SD, loannidis JP, Feero WG, Janssens AC, Gwinn M, Simons-Morton DG, Bernhardt JM, Cargill M, et al: The Scientific Foundation for personal genomics: recommendations from a National Institutes of Health-Centers for Disease Control and Prevention multidisciplinary workshop. Genet Med 2009, 11(8):559-567.

24. Bagos PG, Elefsinioti AL, Nikolopoulos GK, Hamodrakas SJ: The GNB3 C825T polymorphism and essential hypertension: a meta-analysis of 34 studies including 14,094 cases and 17,760 controls. J Hypertens 2007, 25(3):487-500.

25. Pereira TV, Nunes AC, Rudnicki M, Yamada Y, Pereira AC, Krieger JE: Meta-analysis of the association of 4 angiotensinogen polymorphisms with essential hypertension: a role beyond M235T? Hypertension 2008, 51(3):778-783.

26. Phillips CM: Nutrigenetics and metabolic disease: current status and implications for personalised nutrition. Nutrients 2013, 5(1):32-57.

27. Hutson SP: Attitudes and psychological impact of genetic testing, genetic counseling, and breast cancer risk assessment among women at increased risk. Oncol Nurs Forum 2003, 30(2):241-246.

28. Scheuner MT, Sieverding P, Shekelle PG: Delivery of genomic medicine for common chronic adult diseases: a systematic review. JAMA 2008, 299(11):1320-1334.

29. Cyr A, Dunnagan TA, Haynes G: Efficacy of the health belief model for predicting intention to pursue genetic testing for colorectal cancer. $J$ Genet Couns 2010, 19(2):174-186.

30. Jones DL, Clayton EW: The role of distress in uptake and response to predisposition genetic testing: the BMPR2 experience. Genet Test Mol Biomarkers 2012, 16(3):203-209.

31. Bloss CS, Schork NJ, Topol EJ: Effect of direct-to-consumer genomewide profiling to assess disease risk. N Engl J Med 2011, 364(6):524-534.

32. James KM, Cowl CT, Tilburt JC, Sinicrope PS, Robinson ME, Frimannsdottir KR, Tiedje K, Koenig BA: Impact of direct-to-consumer predictive genomic 
testing on risk perception and worry among patients receiving routine care in a preventive health clinic. Mayo Clin Proc 2011, 86(10):933-940.

33. Bredart A, Kop JL, Depauw A, Caron O, Sultan S, Leblond D, Fajac A,

Buecher B, Gauthier-Villars M, Nogues C, et al: Short-term psychological impact of the BRCA $1 / 2$ test result in women with breast cancer according to their perceived probability of genetic predisposition to cancer. Br J Cancer 2013, 108(5):1012-1020.

34. Offit K: Genomic profiles for disease risk: predictive or premature? JAMA 2008, 299(11):1353-1355.

35. Hashimoto T, Yagami F, Owada M, Sugawara T, Kawamura M: Salt preference according to a questionnaire vs. dietary salt intake estimated by a spot urine method in participants at a health check-up center. Intern Med 2008, 47(5):399-403.

doi:10.1186/1471-2296-14-149

Cite this article as: Okayama et al:: Primary care patient willingness for genetic testing for salt-sensitive hypertension: a cross sectional study. BMC Family Practice 2013 14:149.

\section{Submit your next manuscript to BioMed Central and take full advantage of:}

- Convenient online submission

- Thorough peer review

- No space constraints or color figure charges

- Immediate publication on acceptance

- Inclusion in PubMed, CAS, Scopus and Google Scholar

- Research which is freely available for redistribution 